\title{
Viable Airborne Fungi of Outdoor Environments of Yunusemre District, Manisa, Turkey
}

\author{
Fatih Kalyoncu* \\ Manisa Celal Bayar University, Faculty of Science and Letters, Department of Biology, Manisa, Turkey \\ *fatihkalyoncu@ hotmail.com \\ Received: 12 March 2019 \\ Accepted: 11 September 2019 \\ DOI: $10.18466 /$ cbayarfbe. 538722
}

\begin{abstract}
This research is on the viable air fungi was sampling during 12 months in the different points of Yunusemre. Fungal propagules were collected each month from eight isolation points. The concentrations of fungi were reported as $\mathrm{cfu} / \mathrm{m}^{3}$ of air. Fungal identification was made according to their micro and macro morphological characters through the literature. As a result, the average concentration of culturable fungi is $412 \mathrm{cfu} / \mathrm{m}^{3}$ in Yunusemre air. 36 species in 9 genus were identified in this research. Penicillium is the most plenty genus that more than $33 \%$ of the all isolated fungi. Cladosporium was the preponderant fungal genus.
\end{abstract}

Keywords: Airborne fungi, bioaerosol, fungal allergy, outdoor air, Yunusemre.

\section{Introduction}

Atmospheric aerosol that particles of different sizes, shapes and origin in the outdoor and indoor air [1]. This particles classified as biological (fungal cells or spores, bacteria, viruses, pollens, protozoa and algae), chemical and physical [2]. Fungal particles (spores and cells) are generally common organisms in the air. They correlated with air pollution and some health effects on plants, animals and humans [3]. Fungi may cause great damages on historical artifacts because they have biodeteriogenic capacity of organic substances [4]. Also, airborne particles associated with an increased respiratory symptoms (wheezing, coughing, COPD and allergy) and decreased lung capacity [5].

In 1726, an asthma attack that caused by fungal particles reported [6]. Today, more than a hundred fungus are recognized as allergens [7], and they are involved with some human, animal and plant infections [8]. Many studies about fungal biodiversity in the air were carried out for determination of their effects on the humans [9].

Cells and spores of fungi are found in concentrations and varieties according as geographic location, the substrate type (inorganic / organic), climatic conditions of air, and isolation methods [2]. The dominant fungal genera in the air reported that Alternaria, Aspergillus, Cladosporium and Penicillium [3]. However, little known about the fungal biodiversity in Yunusemre district. Therefore, it is inevitable to survey on diversity of air fungi across different points in Yunusemre. Eight isolation points were selected for the study depending on different characters (agrarian, rural and urban) in Yunusemre. The main goal of this research were to determine that the diversity of viable fungi in the air of outdoor environments in Yunusemre.

\section{Materials and Methods \\ 2.1. Sampling Sites}

Yunusemre (211.673 inhabitants) is in the Manisa city, west Turkey. The average altitude is $75 \mathrm{~m}$. It has continental climate and the mean annual temperature is $17.025{ }^{\circ} \mathrm{C}$, the mean annual relative humidity is $68.64 \%$ and the mean annual rainfall is $730 \mathrm{~kg} / \mathrm{m}^{2}$. In January; the average temperature is $6.8{ }^{\circ} \mathrm{C}$, and in July; the average temperature is $27.1^{\circ} \mathrm{C}$. The least rains takes place in the summer, and the most in winter. The snowy day's number is less than five per year. The prepotent wind direction is $\mathrm{S}$ or SE. Climatic data was supplied by the Meteorological Branch Office, Manisa. This research was conducted on eight sampling points in Yunusemre. The ostensible characters of the sampling points are given in Table 1.

Table 1. Some features of the selected sampling sites.

\begin{tabular}{|c|c|c|c|}
\hline No & Name & Locality Coordinate & Altitude \\
\hline 1 & Karakoca & $\begin{array}{c}38^{\circ} 33^{\prime} 26.65^{\prime \prime} \mathrm{N} / \\
27^{\circ} 19^{\prime} 52.38^{\prime \prime} \mathrm{E}\end{array}$ & $467 \mathrm{~m}$ \\
\hline 2 & Keçiliköy & $\begin{array}{c}38^{\circ} 36^{\prime} 23.56 " \mathrm{~N} / \\
27^{\circ} 22^{\prime} 06.71^{\prime \prime} \mathrm{E}\end{array}$ & $149 \mathrm{~m}$ \\
\hline 3 & $\begin{array}{c}\text { YSE } \\
\text { Square }\end{array}$ & $\begin{array}{c}38^{\circ} 36^{\prime} 56.65^{\prime \prime} \mathrm{N} / \\
27^{\circ} 24^{\prime} 12.21^{\prime \prime} \mathrm{E}\end{array}$ & $72 \mathrm{~m}$ \\
\hline 4 & Bozköy & $\begin{array}{c}38^{\circ} 36^{\prime} 39.71 " \mathrm{~N} / \\
27^{\circ} 23^{\prime} 23.35^{\prime \prime} \mathrm{E}\end{array}$ & $112 \mathrm{~m}$ \\
\hline 5 & $\begin{array}{c}\text { Ingolstadt } \\
\text { Avenue }\end{array}$ & $\begin{array}{c}38^{\circ} 37^{\prime} 32.42^{\prime \prime N} / \\
27^{\circ} 23^{\prime} 04.72^{\prime \prime} \mathrm{E}\end{array}$ & $67 \mathrm{~m}$ \\
\hline
\end{tabular}




\begin{tabular}{cccc}
\hline 6 & Horozköy & $\begin{array}{c}38^{\circ} 38^{\prime} 06.07 " \mathrm{~N} / \\
27^{\circ} 23^{\prime} 38.79^{\prime \prime} \mathrm{E}\end{array}$ \\
& & $47 \mathrm{~m}$ \\
7 & Muradiye & $\begin{array}{c}38^{\circ} 39^{\prime} 11.38^{\prime \prime} \mathrm{N} / \\
27^{\circ} 19^{\prime} 59.17^{\prime \prime} \mathrm{E}\end{array}$ \\
& & $33 \mathrm{~m}$ \\
8 & Osmancali & $\begin{array}{c}38^{\circ} 45^{\prime} 43.58^{\prime \prime} \mathrm{N} / \\
27^{\circ} 15^{\prime} 06.56^{\prime \prime} \mathrm{E}\end{array}$ \\
\hline
\end{tabular}

\subsection{Sampling, Isolation and Identification}

Air samples were collected from the eight isolation points between January and December monthly, using gravimetric method [10]. Samples were taken when the weather was dry and stable at the between $08.00-10.00$. Fungal particles were collected in five Petri dishes containing RBCA (Rosebengal Chloramphenicol Agar) were open to air for $20 \mathrm{~min}$ in all isolation points. Totally, 480 samples were taken during the study. Incubation temperature of the Petri dishes was $27^{\circ} \mathrm{C}$, and examined throughout seven-ten days for counting of fungal colonies [11]. The cfu $/ \mathrm{m}^{3}$ of air was calculated according to Omelyansky formula [12];

$N=5 a \times 10^{4}(b t)^{-1}[N$ is the fungal concentration; $a$ is the fungal colony number per Petri; $b$ is the area of plate $\left(\mathrm{cm}^{2}\right)$; and $t$ is the open time of Petri ( $\left.\left.\mathrm{min}\right)\right]$

Identification of fungal colonies by using MEA (Malt Extract Agar), PDA (Potato Dextrose Agar), CZ (Czapek Dox Agar), CYA (Czapek Yeast Agar) and G25N (Glycerol Nitrate Agar) and incubated at $27{ }^{\circ} \mathrm{C}$ for $7-10$ days, after that diameters of colonies were measured. The stereomicroscope and a high resolution light microscope used to for determine that the colonial and morphological characters [13]. Species level identification of isolated fungi were done according to different mycological references [14-17]. All fungal isolates save in Manisa Celal Bayar University, Biology Department.

\section{Results and Discussion}

All fungi isolated in eight sampling points in Yunusemre air are listed in the Table 2. 480 samples were collected by gravimetric method during the one year. Totally, 9628 colonies were counted and the fungal isolates showed 9 genera and 36 species from the air. Also the average concentration of airborne culturable fungi is $412 \mathrm{cfu} / \mathrm{m}^{3}$ in Yunusemre.

As a results, the commonly prevalent genus was Cladosporium (Table 2). The preponderant fungus was Cladosporium herbarum. Penicillium species were more than $33 \%$ of the total isolated fungal species (Table 2). Other genera (Rhizopus, Trichoderma, Fusarium, Mucor and Cunninghamella) were found in according to references [5, 9-11]. In October, September and November; high fungal propagules densities were observed $\left(570,505\right.$ and $460 \mathrm{cfu} / \mathrm{m}^{3}$, respectively). The months in which least fungi were observed were January, April and March (140, 210 and $290 \mathrm{cfu} / \mathrm{m}^{3}$, respectively) (Figure 1).

Many of fungi found in this research are known to may cause allergy. Examples are Alternaria alternata, Cladosporium herbarum, $C$. cladosporoides, $C$. sphaerospermum, Aspergillus flavus, A. fumigatus, A. niger var. niger, Mucor racemosus, Penicillium brevicompactum, $P$. chrysogenum, $P$. citrinum and $P$. expansum $[10,11]$ (Table 2). Tilak [18], related the \% 230 of the respiratory allergies to fungal spores. He also reported Alternaria and Cladosporium species to be the most allergy causing fungi. Also, some fungi that found in this research are known to produce mycotoxins. These are Alternaria alternate, A. tenuissima, Aspergillus flavus, A. fumigatus, A. niger var. niger, A. parasiticus, A. terreus, A. versicolor, Fusarium equiseti, $F$. oxysporum, Penicillium brevicompactum, $P$. chrysogenum, $P$. citrinum, $P$. expansum and $P$. viridicatum $[19,20]$. This study has shown that fungi which can cause the respiratory system diseases and produce mycotoxins were encountered frequently in the sampling areas.

\section{Conclusion}

Aeromycological studies are important to understand the diversity of fungi by air, their distribution, and to derive strategies for to control fungal diseases [21]. This research is the first study in Yunusemre air. In this work, we identified 36 fungus species in the sampling air.

Yunusemre has suitable habitat for diversity of fungi according to its climatic conditions. As a result, a high percentage of fungal particles in air may cause allergy [11] and asthma [10]. Isolating and identifying of fungi will be a useful contribution to the community health departments. Details of the diversity of them in the different areas may be of assistance for the treatment of allergic diseases.

Table 2. Fungal species and sampling sites.

\begin{tabular}{|c|c|c|c|c|c|c|c|c|}
\hline Sampling Sites & 1 & 2 & 3 & 4 & 5 & 6 & 7 & 8 \\
\hline *Alternaria alternata (Fr.) Keissl. & + & + & & & + & + & + & + \\
\hline A. brassicicola (Schwein.) Wiltshire & + & + & + & + & & & & + \\
\hline A. tenuissima (Kunze) Wiltshire & & + & + & + & & + & & \\
\hline *Aspergillus flavus Link & & + & & + & + & + & & + \\
\hline *A. fumigatus Fresen. & & + & + & + & + & & & \\
\hline
\end{tabular}


A. glaucus (L.) Link

*A. niger var. niger Tiegh.

A. parasiticus Speare

A. rubrobrunneus Samson \& W. Gams

A. terreus Thom

A. versicolor (Vuill.) Tirab

A. wentii Wehmer

Cladosporium cladosporioides Fresen.

*C. herbarum (Pers.) Link

*C. oxysporum Berk. \& M.A. Curtis

${ }^{*}$ C. sphaerospermum Penz.

Cunninghamella echinulata Thaxt.

Fusarium equiseti (Corda) Sacc.

F.oxysporum Schltdl.

*Mucor racemosus Fresen.

*Penicillium brevicompactum Dierckx

*P. chrysogenum Thom

*P. citrinum Thom

$P$. digitatum (Pers.) Sacc.

*P. expansum Link

P. funiculosum Thom

P. glabrum Wehmer

$P$. italicum Wehmer

P. lanosum Westling

P. purpurogenum Stoll

$P$. verruculosum Dierckx

$P$. viridicatum Westling

Rhizopus oryzae Went \& Prins

$R$. stolonifer var. stolonifer Ehrenb.

Trichoderma hamatum Bonord.

T. viride Pers.

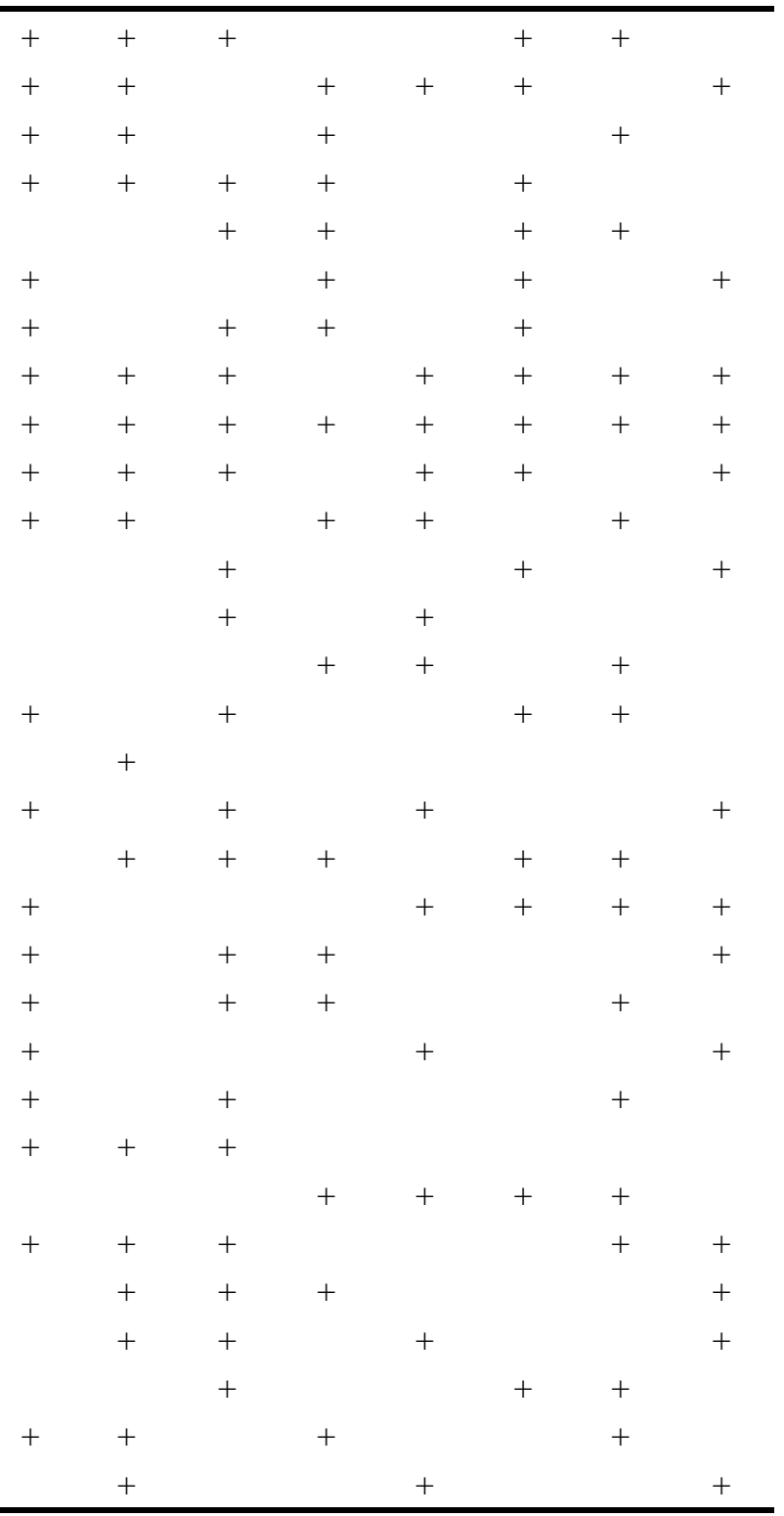

*known as allergen 


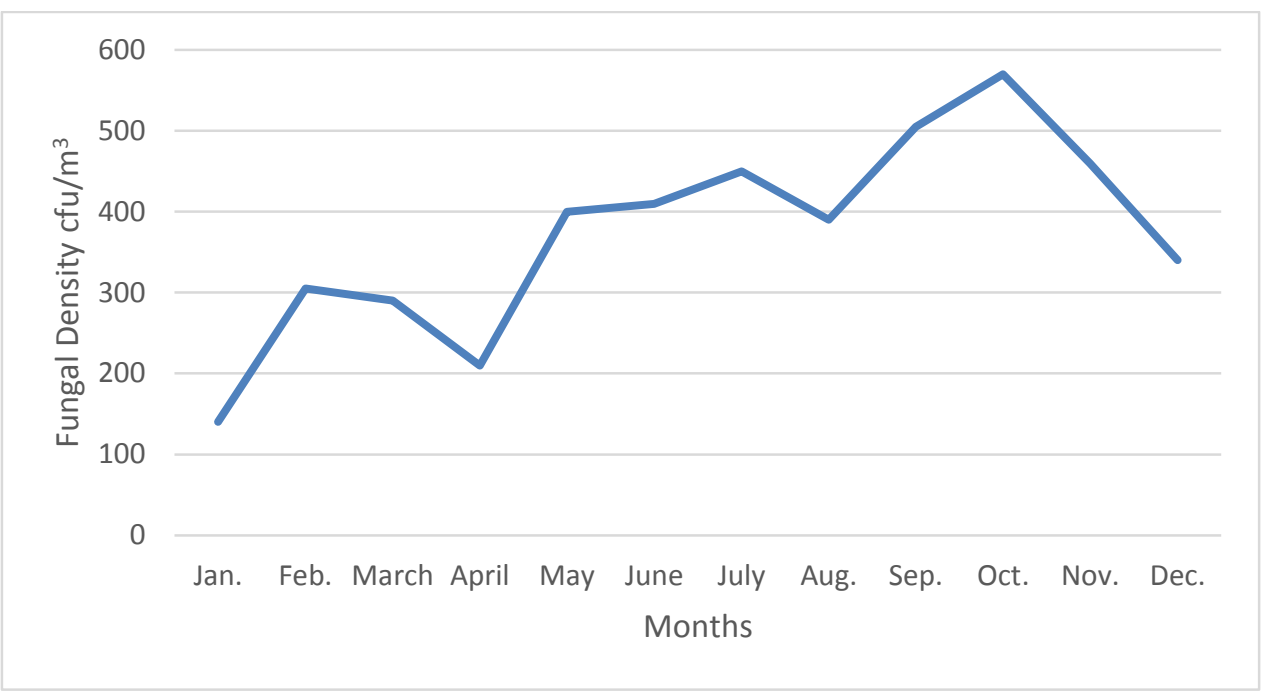

Fig. 1. Fungal spore densities by months.

\section{Ethics}

There are no ethical issues after the publication of this manuscript.

\section{References}

1. Hussein, K, Hargreaves, M, Smith, J, Ristovsky, Z, Agranovsky, V, Morawska, L. 2008. Performance of UVAPS with respect to detection of airborne fungi. Journal of Aerosol Science; 39: 175189.

2. Anaya, M, Borrego, SF, Gamez, E, Castro, M, Molina, A, Valdes, O. 2016. Viable fungi in the air of indoor environments of the National Archive of the Republic of Cuba. Aerobiologia; 32: 513 527.

3. Kalyoncu, F. 2010. Relationship between airborne fungal allergens and meteorological factors in Manisa city, Turkey. Environmental Monitoring Assessments; 165: 553-558.

4. Borrego, S, Perdomo, I. 2012. Aerobiological investigations inside repositories of the National Archive of the Republic of Cuba. Aerobiologia; 28: 303-316.

5. Fang, Z, Ouyang, Z, Hu, L, Wang, XZ, H, LX. 2005. Culturable airborne fungi in outdoor environments in Beijing, China. Science and Total Environment; 350: 47-58.

6. Sadys, M, Adams-Groom, B, Herbert, RJ, Kennedy, R. 2016. Comparison of fungal spore distributions using air sampling at Worcester, England (2006-2010). Aerobiologia; 32: 619-634.

7. Levetin, E, Horner, WE, Scott, JA. 2016. Taxonomy of allergenic fungi. Journal of Allergy Clinical Immunology; 4(3): 375-385.

8. Cvetnic, Z, Pepeljnjak, S. 1997. Distribution and mycotoxinproducing ability of some fungal isolates from the air. Atmospheric Environment; 31(3): 491-495.

9. Adhikari, A, Sen, MM, Bhattcharya, SG, Chanda, S. 2004 Airborne viable, non-viable and allergenic fungi in a rural agricultural area of India. Science and Total Environment; 326 : $123-141$.

10. Gelincik, AA, Buyukozturk, S, Gul, H, Gungor, G, Issever, H, Cagatay, A. 2005. The effects of indoor fungi on the symptoms of patients with allergic rhinitis in Istanbul. Indoor Built Environment; 14: 427-432.

11. Colakoglu, G. 2004. Indoor and outdoor mycoflora in the different districts of the city of Istanbul (Turkey). Indoor Built Environment; 13: $91-100$.

12. Grbic, ML, Stupar, M, Vukojevic, J, Maricic, I, Bungur, N. 2013.Molds in museum environments: 2013. Biodeterioration of art photographs and wooden sculptures. Archives of Biological Science; 65 (3): 955-962.

13. Asan, A, İlhan, S, Șen, B, Erkara, IP, Filik, C, Çabuk, A, Demirel, R, Türe, M, Okten, SS, Tokur, S. 2004. Airborne fungi and actinomycetes concentrations in the air of Eskişehir City (Turkey). Indoor Built Environment; 13: 63-74.

14. Domsch, KH, Gams, W, Anderson, TH. Compendium of Soil Fungi. Volume: 1-2, Academic Press, 1980.

15. Samson, RA, Pitt, JI. Integration of Modern Taxonomic Methods for Penicillium and Aspergillus Classification. Harwood Academic Publishers, Amsteldijk, ISBN: 978-9058231598, 2000.

16. Klich, MA. Identification of common Aspergillus species. First Edition, CBS Publication, Utrecht, ISBN: 978-9070351465, 2002.

17. Samson, RA, Hoekstra, ES, Frisvad, JC. Introduction to food and airborne fungi. CBS Publication, Holland, ISBN: 9789070351526, 2004.

18. Tilak, ST. 1991. Fungal spores and allergy. Journal of Palynology; 27: 369-389.

19. Picco, AM, Rodolfi, M. 2000. Airborne fungi as biocontaminants at two Milan underground stations. International Journal of Biodeterioration and Biodegradation; 45: 43-47.

20. Su, HJJ, Chen, HL, Huang, CF, Lin, CY, Li, FC, Milton, DK. 2002. Airborne fungi and endotoxin concentrations in different areas within textile plants in Taiwan. Environmental Research Section; 89: 58-65.

21. Valle-Aguirre, G, Velazquez-del Valle, MG, Corona-Rangel, ML, Amora-Lazcano, E, Hernandez-Lauzardo, AN. 2016. First aeromycological study in an avocado agroecosystem in Mexico. Aerobiologia; 32: 657-667. 